\title{
Proteome Mining of Sortase A Dependent Proteins (SDPs) in Lactic Acid Bacteria and Docking Analysis of SDPs Interaction with Sortase A
}

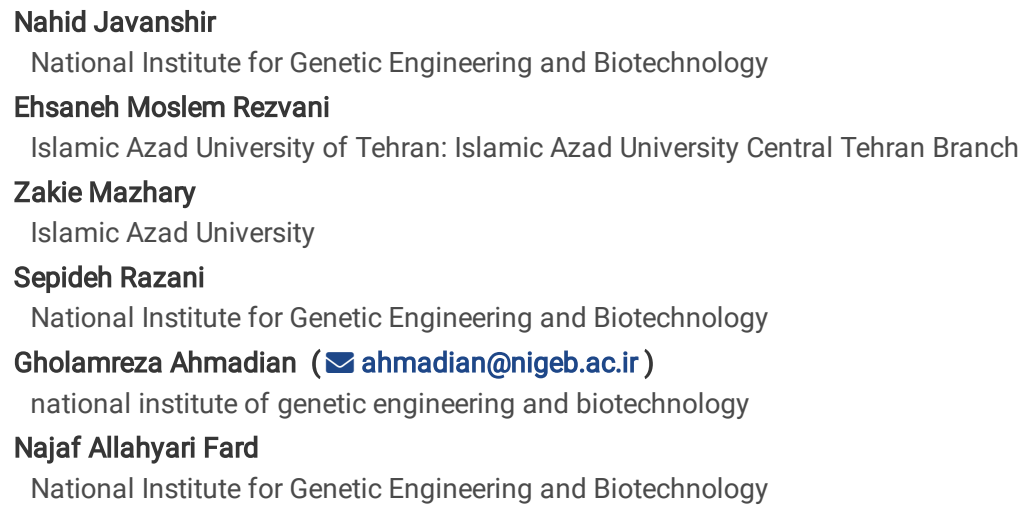




\section{Abstract}

Background: Lactic acid bacteria (LAB), which are important probiotics, play a fundamental role in ensuring the health of the gastrointestinal tract, maintaining the microbiome balance, and preventing the gastrointestinal (GI) tract disorder. One of the effective mechanisms in the bacterial-host interaction is related to the action of the enzyme sortase $A$ and Sortase Dependent Proteins (SDPs). Sortase plays an important role in the stabilization and retention of the probiotic in the gut by exposing various SDPs on the bacterial surface proteins which is involved in the attachment of bacteria to the host intestine and retention in the gut.

Methods: The present study aimes to identify and investigate the abundance of sortase A-dependent proteins (SDPs) in lactic acide bacteria, as well as the frequency analysis of X residue in the sortase recognition and cleavage LPXTG motif and its effect on the interaction between sortase and SDPs. For this purpose, genomic and proteomic sequences of 165 LABs including 119 Lactobacilli, 29 Enterococci, 8 Lactococci, 5 Carnobacteria, and 4 Leuconostocs, were extracted from UniProt and Genome NCBI databases,. for this, we designed ProtScreen software with the ability to recognize a specific motif and domain in the proteome, which is available at http://nigebprotscreen.com/. Also interactions between sortase A and LPXTG motif with 18 different amino acids in X position were determined using in silico approach. The structure of the sortase A enzyme and a SDP in Lactobacillus acidophilus was used for docking using HADDOCK and CABS-dock tools

Results: In this study, out of 165 LABs reference proteomes, there were 25 SDP-free strains. Among the 140 strains with SDPs, 707 proteins were found with the potential to function as SDPs. In this way, ProtScreen software with the ability to recognize a specific motif and domain in the proteome, which is available at http://nigebprotscreen.com/ was designed. Also a database including 707 SDPs in Lactobacillus, Enterococcus, Lactococcus, Carnobacterium, and Leuconostoc strains was designed which is available in the project section at online ProtScreen software. Our results showed that the most abundant amino acid in X position in the LPXTG motif among 165(LABs) is glutamine (Q). Results of SDPs and sortase A docking using HADDOCK and CABS-dock tools, showed that the highest binding energy is related to the glutamine, where a positive relationship between frequency of amino acids and binding energy was observed. Therefore, our data shows that why glutamine in nature and during evolution, has been selected as the best amino acid for X site in LPXTG motif.

Conclusions: The results of the present research and similar studies could be useful in better understanding the role of sortase A and SDPs in the studies on the mechanisms related to the interactions between bacteria and the host, including longer probiotic persistence in the gut.

\section{Background}

Nowadays, besides the fundamental role of foods in providing the necessary nutrients for the growth and development of organisms, some other foods containing probiotics have also been found to be important for good health and fighting diseases. Lactic acid bacteria (LABs), which are members of the Lactobacillus and Bifidobacterium genera, are often used as probiotics $(3,4)$. Moreover, LABs are a group of gram-positive bacteria identified by their specific morphological, metabolic, and physiological characteristics. Also, these bacteria, which are known to produce lactic acid as a by-product of glucose catabolism, always play important roles in maintaining human health $(5,6)$. Notably, the mechanisms that are involved in the activity of LAB strains against bacterial pathogens include the production of hydrogen peroxide, lactic acid, bacteriocin-like molecules, stimulation of the immune system, and changes in gut microbiota (7). Besides, LABs prevents pathogens from adhering to the gut by competing for adhesion sites in intestinal epithelial cells, thereby reducing pathogen colonization as well as the risk of infection $(8,9)$.

To exert some positive effects by a probiotic strain, firstly, it must be able to adhere to intestinal cells and form a biofilm (10,11). The genomes of all grampositive bacteria, a small number of gram-negative bacteria, as well as some archaea, encode cysteine transpeptidase enzymes are called sortase (12-14). Accordingly, these enzymes covalently bind proteins to the bacterial cell wall, thus playing an important role in the regulation of the surface structure of microorganisms (15).

Sortase has been divided in classes of $A, B, C, D, E$, and $F(16)$. In this regard, class A sortase is present in many Gram-positive bacteria, which is a housekeeping protein responsible for the covalent binding of proteins with the LPXTG motif to the bacterial cell wall $(17,18)$. Class B sortase plays a role in iron homeostasis by binding the iron uptake proteins to the cell wall via the NP (Q / K) TN motif (19). class $C$ sortase plays a role in the polymerization of pili constituents via the motif ( / L) (P / A) XTG $(20,21)$. Class D sortase plays a role in the binding of proteins involved in spore formation through the LPNTA motif, as well as the functions of class $F$ and $E$ sortase, which are generally identified in Acinetobacter (22). Sortases are responsible for adhesion and stabilization of a group of surface proteins called SDPs to the gram-positive bacterial cell wall by covalently identifying, breaking, and binding a specific conserved motif (e.g. LPXTG motif in Class A sortase) (22). To ensure the successful adhesion of SDPs to the cell wall, besides having an LPXTG motif, it is essential to ensure a proper hydrophobicity in the C-terminal region as well as a positively charged tail at the carboxy-terminal Domain (CTD) (23).

Sortase enzymes are considered as pathogenic factors in pathogenic bacteria because they play several vital pathological roles such as adhesion, food supply, and escape from the immune system (24-26). However, these enzymes that are also present in gram-positive probiotic bacteria like LABs, which have nutritional value and health-promoting effect, have been shown to play an important role in the bacteria-host interaction (23). Sortase have also become an attractive target for studying bacteria-host interaction considering its role in the binding of some proteins to the cell wall. $(19,27)$. The mechanism of action of sortase is important for the expression of proteins on the cell surface as well as its role in host-bacteria interactions, which also plays a prominent place in the functions of probiotic and commensal bacteria related to intestinal mucosal membranes. Therefore, it is possible to predict the mechanism of action of sortase in LABs in probiotic strains. Considering the essential role of sortase in binding its substrate to the cell wall in gram-positive bacteria and the vital importance of a proper adhesion to epithelial cells in improving the functions of probiotic bacteria, SDPs are predicted to play a key role in strengthening and also improving the adhesion of probiotic bacteria, especially some strains like lactobacillus. Therefore, investigating the frequency and type of sortase substrates in LABs is important to identify the functions and benefiting from the beneficial effects of this group of bacteria. Therefore, the present study identifies SDPs in 165 LAB strains using bioinformatics tools, along with investigating their physical, chemical, and structural properties. In addition the 
performance of different amino acids at the X site using molecular docking along with the effect on the interaction between SDPs and sortase A in lactic acid bacteria were investigated.

By elucidating the three-dimensional structure of protein complexes, a thorough understanding of the mechanisms of molecular recognition and interaction can be achieved (28). In this study, an information-driven from docking approach has been applied to the interaction between sortase A and a penta-peptide representing sortase cleavage motif in SDPs, which represent an essential step in a bacterial attachment to the intestinal cell epithelium and its retention in the gut.

\section{Materials And Methods}

\subsection{Designing ProtScreen software}

A software was designed with the ability to recognize a specific motif and domain in the proteome. Accordingly, in this software, which is available online at http://nigebprotscreen.com/. The protein sequence as a FASTA format and the desired motif is uploaded to find the motif in the proteome the outcome would be Motif name and the UniPort ID of the protein containing that Motif.

Also a Database was designed that includes SDPs in Lactobacillus, Enterococcus, Lactococcus, Carnobacterium, and Leuconostoc strains which is available in the project section at the above-mentioned site. By entering the name of the organism, information such as UniPort ID, Protein Name, Motif, and Motif Position is obtained. The motif discovery application and SDP database are written in Java and IntelliJ environment, and run using Tom Cat 7.0.64 and JDK 1.7 , respectively.

\subsection{Identifying SDPs with LPXTG motif}

At first, ProtScreen software was used to identify the SDPs. The reference protein and genome of 165 LAB strains, including 119 Lactobacilli, 29 Enterococci, 8 Lactococci, 5 Carnobacteria, and 4 Leuconostocs, were investigated. After the sequence analysis, the proteins with the LPXTG motif were identified.

\subsection{Investigating the presence of peptide signal}

Considering that it is necessary to have a secretory signal peptide in the N-terminal of SDPs, we investigated the presence of signal peptide (SP) in the proteins obtained from the previous step with LPXTG motif using the relevant online software named SignalP-5.0 at http://www.cbs.dtu.dk/services/SignalP/.

SignalP-5.0 offers a deep neural network-based approach that improves SP prediction across all domains of life, and also distinguishes three forms of prokaryotic SPs. Moreover, a Sec signal peptide (Sec / SPI), a Lipoprotein signal peptide (Sec / SPII), a Tat signal peptide (Tat / SPI) or No signal peptide at all (Other) may be present in the protein (29).

\subsection{Hydrophobicity of C-terminal Region}

To investigate the hydrophobicity at the C-terminal region of proteins containing SP, the ExPASy portal, https://www.expasy.org/was used.

An amino acid scale is defined by an assigned numerical value for each type of amino acids. In this regard, hydrophobicity or hydrophilicity scales and secondary structure conformational parameters scales are the most commonly used scales; however, many other scales are based on different chemical and physical properties of amino acids. ProtScale on the ExPASy server contains 57 predefined scales input from the literature (30).

\subsection{Investigation of amino acid abundance at the $x$ site of LPXTG motif in SDPs}

In this study, the abundance of $\mathrm{x}$ amino acids in LPXTG motif in SDPs was investigated across ProtScreen database at http://nigebprotscreen.com/. This database contains 707 SDPs of 165 species of lactic acid bacteria, including Lactobacillus, Enterococcus, Lactococcus, Carnobacterium, and Leuconostoc.

\subsection{Investigation of the structure of proteins and modeling an appropriate structure}

To use 3D structures for docking, all 707 SDPs as well as the structure of the sortase A enzyme in all of the above strains were studied using the UniProt database at https://www.uniprot.org/ to separate suitable structures for docking. To determine the structure of sortase A and SDPs, SWISS-MODEL structure prediction software at https://swissmodel.expa sy.org/ was used to predict the structure of SDPs. The models were evaluated and validated using ProSA-web servers (https://prosa.services.came.sbg.ac.at/prosa.php) and Ramachandran map analysis (http://molprobity.biochem.duke.edu ).

\subsection{Sortase A structure selection}

Investigation of sortases in strains with SDP showed that there are only four cases of sortases with the known structure in the UniProt database, whose identities included F9UKZ1 (F9UKZ1_LACPL) in Lactobacillus plantarum (strain ATCC BAA-793 / NCIMB 8826 / WCFS1), Q5FJP7 (Q5FJP7_LACAC) in Lactobacillus acidophilus (strain ATCC 700396 / NCK56 / N2 / NCFM), Q836L7 (Q836L7_ENTFA) in Enterococcus faecalis (strain ATCC 700802 / V583) and Q82ZJ9 (Q82ZJ9_ENTFA) in Enterococcus faecalis (strain ATCC 700802 / V583). Because the aim of this study was investigating the probiotic strains, L. acidophilus strain was used to select SDPs in this strain and to model its structure as well as for docking.

\subsection{Identification of the appropriate structure of the SDPs}

Among 707 SDPs in the ProtScreen database to separate the appropriate structure, it was found that only two of them had the known structure in the UniProt database with ID of ASA1_ENTFA (with LPQTG motif) in the strain Enterococcus faecalis (strain ATCC 700802 / V583) and Q3Y373_ENTFD (with LPETG motif) in Enterococcus faecium strain (ATCC strain BAA-472 / TX0016 / DO). Considering the pathogenicity of the above strains, these structures were not used for docking with sortase A. Because the structure of the sortase A in the strains of Lactobacillus acidophilus (strain ATCC 700396 / NCK56 / N2 / NCFM) 
and Lactobacillus plantarum (strain ATCC BAA-793 / NCIMB 8826 / WCFS1) was known, the SDPs structure in these strains were used for docking. There were 5 SDPs with unknown structures in L. acidophilus strain and 6 SDPs in L. plantarum strain. Out of a total of 11 SDPs in these two strains, the structure was determined for only one of the SDPs in Lactobacillus acidophilus based on the SWISS-MODEL results. The above SDP identification code in UniProt is: Q5FLL3_LACAC. The LPTTG motif is present in this SDP.

\subsection{Molecular docking using HADDOCK and CABS-DOCK}

Docking of SDPs with sortase A in Lactobacillus acidophilus strain (strain ATCC 700396/NCK56/N2/) was studied using HADD0CK2.2 and CABSdock software at https://haddock.science.uu.nl/services/HADDOCK2.2/ and http://biocomp.chem.uw.edu.pl/CABSdock. In this study, 18 amino acids were evaluated at the $X$ site in the LPXTG motif in the SDP recognized in Lactobacillus acidophilus with the UniProt ID Q5FLL3_LACAC and sortase A with the UniProt ID Q5FJP7_LACAC (which had the TLXTC motif in its active site). The reason for checking only 18 amino acids out of the 20 amino acids was that the two amino acids cysteine and tryptophan were not present in the studies on the abundance of the amino acid X in the LPXTG motif in 707 SDPs. Thus, they were not considered for further study.

HADDOCK is a versatile flexible docking approach for modeling biomolecular complexes. HADDOCK differentiates itself from ab-initio docking approaches in that it can incorporate knowledge derived from biochemical, biophysical, or bioinformatics methods to enhance sampling, scoring, or both. The knowledge it can incorporate is very varied: device constraints NMR or MS interface constraints, mutagenesis tests, or bioinformatics predictions; various NMR orientation constraints and, more recently, cryo-electron maps. HADDOCK currently allows the simulation of large assemblies consisting of up to 6 different molecules, offering a truly integrative simulation platform along with its rich data support (31).

The web server CABS-dock provides an interface for modeling protein - peptide interactions using a highly efficient protocol for modular protein docking of peptides. Although other docking algorithms require predefined binding site localization, such information is not required by CABS-dock. Given the structure of a protein receptor and a peptide sequence (and starting from random conformations and peptide positions), CABS-dock performs simulation search for the binding site allowing complete peptide versatility and small receptor backbone fluctuations (32).

\section{Results}

\subsection{SDP Identification}

2709 proteins with LPXTG motif were identified using ProtScreen software. Of them, 811 proteins had signal peptide. Analysis of hydrophobicity in the Cterminal region of proteins with SDPs showed that 707 proteins had adequate hydrophobicity in the C-terminal region. Finally, these 707 proteins by having the potential of functioning as SDPs, were identified in the studied LABs. In 707 proteins found, 280 were uncharacterized and 427 were characterized. Table 1 compares the number of the characterized SDPs in the studied strains. An additional file shows more detail about identified SDPs [see Additional file 1].

Table 1

The number of SDPs in lactic acid strains.

\begin{tabular}{|llllll|}
\hline Species & Lactobacillus sp. & Enterococcus sp. & Lactococcus sp. & Camobacterium sp. & Leuconostoc sp. \\
\hline Total SDPs number & 361 & 280 & 44 & 16 & 6 \\
\hline
\end{tabular}

Considering the importance of lactobacilli in this group, SDPs in this genus underwent further analysis. Strains with the highest SDPs in terms of the characterized and uncharacterized SDPs are also listed in Table 2.

Table 2

Lactobacillus strains with the highest number of the characterized and uncharacterized SDPs.

\begin{tabular}{|lll|}
\hline $\begin{array}{l}\text { lactobacillus with the highest number of } \\
\text { uncharacterized SDPs }\end{array}$ & $\begin{array}{l}\text { lactobacillus with the highest number of characterized } \\
\text { SDPs }\end{array}$ & $\begin{array}{l}\text { Lactobacillus with the highest number } \\
\text { of SDPs }\end{array}$ \\
\hline Lactobacillus sharpeae JCM 1186 = DSM 20505 & Lactobacillus oris PB013-T2-10 & $\begin{array}{l}\text { Lactobacillus sharpeae JCM 1186 = } \\
\text { DSM 20505 }\end{array}$ \\
\hline Lactobacillus perolens DSM 12744 & Lactobacillus pasteurii DSM 23907 = CRBIP 24.77 & Lactobacillus oris PB013-T2-10 \\
\hline Lactobacillus apis & $\begin{array}{l}\text { Lactobacillus plantarum (strain ATCC BAA-793 / NCIMB } \\
8826 / \text { WCFS1) }\end{array}$ & Lactobacillus apis \\
\hline Lactobacillus nasuensis JCM 17159 & Lactobacillus coleohominis 101-4-CHN & Lactobacillus paucivorans \\
\hline Lactobacillus rossiae DSM 15814 & Lactobacillus paucivorans & Lactobacillus nasuensis JCM 17159 \\
\hline
\end{tabular}

From 119 studied lactobacilli, 42 strains were probiotic, and 77 non-probiotic. Table 3 shows the 5 probiotic and non-probiotic stains with the highest number of SDPs. An additional file shows more detail about LAB and their identified SDPs [see Additional file 2]. 
Table 3

Lactobacillus probiotic and non-probiotic strains with the highest SDPs.

\begin{tabular}{|ll|}
\hline Non probiotic lactobacillus with the highest number of SDPs & Probiotic lactobacillus with the highest number of SDPs \\
\hline Lactobacillus sharpeae & Lactobacillus oris \\
\hline Lactobacillus apis & Lactobacillus perolens \\
\hline Lactobacillus paucivorans & Lactobacillus ingluviei \\
\hline Lactobacillus nasuensis & Lactobacillus johnsonii \\
\hline Lactobacillus hominis & Lactobacillus plantarum \\
\hline
\end{tabular}

\subsection{Investigation of amino acids in the X position of LPXTG motif}

After the investigation of 165 LAB strains as well as identifying the LPXTG motif by sortase A, it can be concluded that glutamine (Q) had the highest frequency in the $X$ position of the identified motifs. Figure 1 demonstrates the number and type of different amino acids found in the $X$ Position.

Also, there were only 18 amino acids (A D E F G H I K L M N P Q R S T V Y) at the X position of 707 SDPs, and two amino acids, cysteine, and tryptophan were not present.

\subsection{Investigation of the interaction between SDPs and sortase A}

LPXTG motif in Lactobacillus acidophilus SDP is LPTTG.

In this SDP (UniProt code: Q5FLL3_LACAC), 18 amino acids including A,D,E,F,G,H,I,K,L,M,N,P,Q,RS,T,V,Y were applied instead of $X$, whose structure was modeled by Swiss model. The models were evaluated and validated using ProSA-web servers and Ramachandran map analysis, as presented in Fig. 2. Protein - protein docking was done by HADDOCK2.2. The two sites that were considered for dockings include: the LPXTG site of SDPS and TLITC site of sortase A. Active residues in the sortase A and SDPs used in docking is shown in Table 4. The results of HADDOCK are reported in Table 5.

Table 4

Active residues in the sortase A and SDPs used in docking

\begin{tabular}{|lll|}
\hline Structure & MOTIF & Active residues \\
\hline Protein1 (Sortase A) & TLITC & $194,195,196,197,198$ \\
\hline Protein2 (SDP) & LPXTG & $226,227,228,229,230$ \\
\hline
\end{tabular}


Table 5

HADDOCK Results for the sortase A-SDP interactions.

\begin{tabular}{|c|c|c|c|c|c|c|c|c|c|c|c|}
\hline $\begin{array}{l}\mathrm{X} \\
\text { residue }\end{array}$ & $\begin{array}{l}\text { Number } \\
\text { of } \\
\text { HADDOCK } \\
\text { clustered } \\
\text { structures }\end{array}$ & $\begin{array}{l}\text { Number } \\
\text { of } \\
\text { clusters }\end{array}$ & $\begin{array}{l}\text { Percentage } \\
\text { of the } \\
\text { water- } \\
\text { refined } \\
\text { models }\end{array}$ & $\begin{array}{l}\text { Z } \\
\text { score }^{a}\end{array}$ & $\begin{array}{l}\text { Haddock } \\
\text { score }^{b} \\
\text { (a.u.) }\end{array}$ & $\begin{array}{l}\text { Top } \\
\text { Cluster } \\
\text { size }^{c}\end{array}$ & $\begin{array}{l}\text { RMSD from } \\
\text { the overall } \\
\text { lowest- } \\
\text { energy } \\
\text { structure }(\AA)\end{array}$ & $\begin{array}{l}\text { Intermolecular } \\
\text { Van der } \\
\text { Waals } \\
\text { energy } \\
\left(E_{\mathrm{vdw}}\right)(\mathrm{kcal} \\
\left.\mathrm{mol}^{-1}\right)\end{array}$ & $\begin{array}{l}\text { Intermolecular } \\
\text { Electrostatic } \\
\text { energy } \\
\left(E_{\text {elec }}\right)\left(k_{c a l}\right. \\
\left.\mathrm{mol}^{-1}\right)\end{array}$ & $\begin{array}{l}\text { Desolvation } \\
\text { energy } \\
\left(E_{\text {desol }}\right)(k \\
\left.\mathrm{mol}^{-1}\right)\end{array}$ & $\begin{array}{l}\text { Restrai } \\
\text { violatic } \\
\text { energy } \\
\left(E_{\text {AIR }}\right) \\
\left(\mathrm{kcal}^{-1}\right. \\
\left.\mathrm{mol}^{-1}\right)\end{array}$ \\
\hline A & 149 & 7 & $74.5 \%$ & -1.8 & $\begin{array}{l}-108.0 \\
+/-7.3\end{array}$ & 9 & $0.7+/-0.4$ & $-44.3+/-3.7$ & $\begin{array}{l}-398.4+/- \\
34.6\end{array}$ & $10.2+/-3.0$ & $\begin{array}{l}57.7+/ \\
19.29\end{array}$ \\
\hline D & 146 & 10 & $73.0 \%$ & -2.3 & $\begin{array}{l}-111.6 \\
+/-8.9\end{array}$ & 5 & $0.7+/-0.5$ & $-45.1+/-3.4$ & $\begin{array}{l}-430.3+/- \\
46.7\end{array}$ & $6.8+/-6.3$ & $\begin{array}{l}127.3+ \\
30.72\end{array}$ \\
\hline$E$ & 158 & 8 & $79.0 \%$ & -2.1 & $\begin{array}{l}-112.7 \\
+/-5.5\end{array}$ & 20 & $0.9+/-0.6$ & $-42.7+/-7.8$ & $\begin{array}{l}-383.6+/- \\
44.0\end{array}$ & $-0.2+/-5.1$ & $\begin{array}{l}69.5+1 \\
30.68\end{array}$ \\
\hline $\mathrm{F}$ & 144 & 9 & $79.0 \%$ & -1.6 & $\begin{array}{l}-88.5+/- \\
1.2\end{array}$ & 94 & $22.7+/-0.8$ & $-31.5+/-3.9$ & $\begin{array}{l}-293.5+/- \\
14.0\end{array}$ & $-7.0+/-7.7$ & $\begin{array}{l}86.8+/ \\
13.64\end{array}$ \\
\hline G & 141 & 10 & $70.5 \%$ & -1.6 & $\begin{array}{l}-84.3+/- \\
18.1\end{array}$ & 4 & $18.2+/-0.3$ & $-45.6+/-6.2$ & $\begin{array}{l}-260.0+/- \\
52.3\end{array}$ & $-1.6+/-6.1$ & $\begin{array}{l}149.2+ \\
39.60\end{array}$ \\
\hline $\mathrm{H}$ & 152 & 9 & $76.0 \%$ & -1.1 & $\begin{array}{l}-92.2+/- \\
23.2\end{array}$ & 4 & $6.4+/-2.2$ & $-31.1+/-1.0$ & $\begin{array}{l}-403.0+/- \\
69.3\end{array}$ & $10.0+/-6.0$ & $\begin{array}{l}95.7+/ \\
54.65\end{array}$ \\
\hline I & 152 & 9 & $76.0 \%$ & -1.5 & $\begin{array}{l}-108.3 \\
+/-2.9\end{array}$ & 10 & $10.3+/-0.2$ & $-40.6+/-3.7$ & $\begin{array}{l}-388.2+/- \\
41.5\end{array}$ & $3.7+/-7.9$ & $\begin{array}{l}61.9+/ \\
20.68\end{array}$ \\
\hline K & 138 & 8 & $69.0 \%$ & -1.3 & $\begin{array}{l}-91.1+/- \\
14.6\end{array}$ & 11 & $18.6+/-2.8$ & $-32.3+/-6.0$ & $\begin{array}{l}-302.9+/- \\
87.1\end{array}$ & $\begin{array}{l}-7.9+/- \\
14.8\end{array}$ & $\begin{array}{l}95.8+/ \\
38.26\end{array}$ \\
\hline L & 154 & 12 & $77.0 \%$ & -1.6 & $\begin{array}{l}-91.0+/- \\
5.5\end{array}$ & 89 & $12.2+/-0.4$ & $-33.3+/-3.8$ & $\begin{array}{l}-301.7+/- \\
26.2\end{array}$ & $-9.6+/-5.9$ & $\begin{array}{l}122.0+ \\
34.85\end{array}$ \\
\hline M & 147 & 10 & $73.5 \%$ & -2.4 & $\begin{array}{l}-107.1 \\
+/-4.7\end{array}$ & 8 & $10.8+/-0.4$ & $-40.2+/-3.6$ & $\begin{array}{l}-384.9+/- \\
12.2\end{array}$ & $0.8+/-4.0$ & $\begin{array}{l}93.1+/ \\
22.38\end{array}$ \\
\hline $\mathrm{N}$ & 145 & 8 & $72.5 \%$ & -1.6 & $\begin{array}{l}-92.1+/- \\
4.0\end{array}$ & 5 & $16.6+/-2.3$ & $-22.4+/-9.5$ & $\begin{array}{l}-375.3+/- \\
22.3\end{array}$ & $-7.2+/-4.7$ & $\begin{array}{l}125.7+ \\
29.34\end{array}$ \\
\hline$P$ & 154 & 10 & $77.0 \%$ & -1.5 & $\begin{array}{l}-94.9+/- \\
2.7\end{array}$ & 87 & $9.7+/-1.5$ & $-25.2+/-2.9$ & $\begin{array}{l}-348.9+/- \\
46.1\end{array}$ & $\begin{array}{l}-12.0+/- \\
5.0\end{array}$ & $\begin{array}{l}120.9+ \\
46.52\end{array}$ \\
\hline Q & 144 & 10 & $72.0 \%$ & -1.5 & $\begin{array}{l}-82.1+/- \\
4.9\end{array}$ & 89 & $12.9+/-0.2$ & $-28.4+/-4.0$ & $\begin{array}{l}-298.6+/- \\
15.9\end{array}$ & $-8.7+/-3.4$ & $\begin{array}{l}147.0+ \\
27.55\end{array}$ \\
\hline $\mathrm{R}$ & 148 & 8 & $74.0 \%$ & -2.2 & $\begin{array}{l}-104.9 \\
+/-7.1\end{array}$ & 12 & $1.1+/-0.7$ & $-39.1+/-2.1$ & $\begin{array}{l}-399.2+/- \\
54.9\end{array}$ & $5.7+/-8.7$ & $\begin{array}{l}83.4+/ \\
54.29\end{array}$ \\
\hline S & 146 & 9 & $73.0 \%$ & -2.4 & $\begin{array}{l}-113.1 \\
+/-8.0\end{array}$ & 5 & $13.6+/-0.6$ & $-43.4+/-2.5$ & $\begin{array}{l}-397.9+/- \\
69.5\end{array}$ & $1.7+/-9.2$ & $\begin{array}{l}81.1+/ \\
28.80\end{array}$ \\
\hline $\mathrm{T}$ & 156 & 9 & $78.0 \%$ & -2.1 & $\begin{array}{l}-97.7+/- \\
4.4\end{array}$ & 8 & $16.8+/-2.3$ & $-40.0+/-3.0$ & $\begin{array}{l}-333.1+/- \\
50.1\end{array}$ & $0.7+/-10.6$ & $\begin{array}{l}82.2+/ \\
26.30\end{array}$ \\
\hline V & 142 & 9 & $71.0 \%$ & -1.6 & $\begin{array}{l}-98.0+/- \\
7.9\end{array}$ & 10 & $0.8+/-0.5$ & $-45.9+/-5.1$ & $\begin{array}{l}-329.8+/- \\
43.4\end{array}$ & $4.6+/-10.4$ & $\begin{array}{l}92.0+/ \\
33.64\end{array}$ \\
\hline Y & 144 & 7 & $72.0 \%$ & -1.7 & $\begin{array}{l}-101.7 \\
+/-4.5\end{array}$ & 9 & $14.0+/-0.5$ & $-41.5+/-2.9$ & $\begin{array}{l}-349.9+/- \\
38.4\end{array}$ & $2.6+/-2.8$ & $\begin{array}{l}72.0+/ \\
34.25\end{array}$ \\
\hline
\end{tabular}

a. Z-score indicates how many standard deviations from the average this cluster is located in terms of score (the more negative the better.

b. The HADDOCK score is defined as: 1.0 Evdw + 0.2 Eelec + 1.0 Edesol + 0.1 EAIR.

c. The top cluster is the most reliable according to HADDOCK.

d. Non-bonded interactions were calculated with the OPLS force field (Jorgensen W, Tirado-Rives J. The OPLS potential functions for proteins. Energy minimizations for crystals of cyclic peptides and crambin. J Am Chem Soc 1988;110(6):1657-1666) using a 8.5 ̊ cut-off.

e. Calculated using the empirical desolvation energy parameters from Fernandez-Recio et al (Fernández-Recio J, Totrov M, Abagyan R. Identification of proteinprotein interaction sites from docking energy landscapes. J Mol Biol 2004;335(3):843-865). 
For docking by CABS-Dock, the protein sequence (UniProt ID: Q5FJP7_LACAC), LPXTG peptide and sortase A were investigated. The protein and peptide sequences are listed in Table 6. The results of docking analysis are also shown in Table 7. Figure 3 shows the interaction between sortase A and LPQTG peptide.

Table 6

Protein sequence (sortase A), peptide sequence of SDPs used in Cabs-Dock

\begin{tabular}{|ll|}
\hline $\begin{array}{l}\text { Protein sequence } \\
\text { Sortase A }\end{array}$ & $\begin{array}{l}\text { QQSALTTLTKKQVEANQKKKGMYDFSKVKSMNMGQAARSQVKKTSGAIGA } \\
\text { LAVPDVNMYLPIMLGLSDDAMSTGGGTMRADQVMGKGNYPLAGHYMTAK } \\
\text { GILFSPLEDVKKGQRIYLTNLKKIYIYRIYMKKIVDPSAVWLVNNTKKNIVTLI } \\
\text { TCADGGTNRWAIRGNLIKTEKATDENLKVFKLK }\end{array}$ \\
\hline $\begin{array}{l}\text { Peptide sequence } \\
\text { In SDP }\end{array}$ & LPXTG $(X=\mathrm{A}, \mathrm{D}, \mathrm{E}, \mathrm{F}, \mathrm{G}, \mathrm{H}, \mathrm{I}, \mathrm{K}, \mathrm{L}, \mathrm{M}, \mathrm{N}, \mathrm{P}, \mathrm{Q}, \mathrm{R}, \mathrm{S}, \mathrm{T}, \mathrm{V}, \mathrm{Y})$ \\
\hline
\end{tabular}

Table 7

Cabs-Dock results for sortase A protein (Q5FJP7_LACAC) and LPXTG peptide

\begin{tabular}{|c|c|c|c|c|}
\hline $\mathrm{X}$ residue & Cluster density & Average cluster RMSD $(\AA)$ & Maximum RMSD within the cluster $(\AA)$ & Number of cluster elements \\
\hline A & 62.8723 & 2.33807 & 20.1578 & 147 \\
\hline D & 74.1737 & 1.84702 & 8.06203 & 137 \\
\hline E & 33.2997 & 3.33336 & 19.5692 & 111 \\
\hline $\mathbf{F}$ & 39.793 & 4.47315 & 23.1951 & 178 \\
\hline G & 43.8823 & 3.66891 & 14.6217 & 161 \\
\hline $\mathrm{H}$ & 122.333 & 0.72752 & 5.06132 & 89 \\
\hline I & 29.7708 & 4.93773 & 15.9555 & 147 \\
\hline K & 44.4985 & 5.05635 & 29.3093 & 225 \\
\hline $\mathbf{L}$ & 45.8788 & 4.51189 & 30.5202 & 207 \\
\hline M & 75.9666 & 1.50066 & 10.2860 & 114 \\
\hline $\mathbf{N}$ & 52.6666 & 5.06962 & 33.0296 & 267 \\
\hline $\mathbf{P}$ & 39.5197 & 3.69436 & 18.2583 & 146 \\
\hline Q & 38.7696 & 2.91465 & 16.3359 & 113 \\
\hline $\mathbf{R}$ & 36.1541 & 4.25954 & 15.433 & 154 \\
\hline S & 32.6392 & 3.06380 & 18.9037 & 100 \\
\hline $\mathrm{T}$ & 38.3878 & 6.04359 & 37.7307 & 232 \\
\hline V & 36.8749 & 3.22713 & 8.52911 & 119 \\
\hline Y & 27.374 & 6.24681 & 34.0621 & 171 \\
\hline
\end{tabular}

Given that the amino acid Q was the most abundant amino acid at the X site in the LPXTG motif in 707 SDPs, which are available in the ProtScreen database, docking results showed that the highest binding energy was related to glutamine amino acid. Also, a positive relationship was observed between frequency and binding energy. This is probably associated with the selectivity of the amino acid Q with lower binding energy, as this binding is the precursor to another reaction called transpeptidase, where the LPXTG motif in SDP cleaves between threonine and glycine and binds to the bacterial cell wall peptidoglycan via nucleophilic amines. Thus, less binding energy in the interaction of the two proteins sortase A and SDP probably has a positive effect on cleavage and continuation of the reaction.

\section{Discussion}

Probiotic products can contain one or more selected starins of bacteria. It is noteworthy that, Human probiotic microorganisms often include Lactobacillus, Bifidobacterium, Lactococcus, Streptococcus, and Enterococcus (33) genera, among which, lactic acid strains are of great importance. According to the WHO, FAO, and EFSA, the strains selected as probiotics should be safe (34). Probiotics offer some benefits to the host by performing various functional mechanisms. Correspondingly, the functional aspects of probiotics are determined by their survival in the gastrointestinal tract and their effects on the immune system (35). Lactic acid bacteria (LAB) have a long-term history of use in food industry and are increasingly used in therapies for their advantages on health effects, and significant biotechnological potentials. The developed systems for engineering are combined with novel approaches, such as CRISPR-Cas, to allow the use of LAB for targeted delivery (36). 
Sortase is an extracellular transpeptidase enzyme in gram-positive bacteria responsible for identifying and covalently binding a group of secretory proteins called SDPs to the gram-positive bacterial cell wall by identifying a specific conserved motif in these proteins (22).

Various classes of sortase have been identified. Including; Class A sortase, a housekeeping protein, Class B sortase, involved in iron homeostasis, Class C sortase responsible for pilin polymerization, Class D sortase, involved in the spore formation and Classes $\mathrm{F}$ and $\mathrm{E}$ A sortases which identified in Acinetobacter. Notably, the sortase enzyme is present in some gram-positive bacteria, and the members of the lactic acid family are not exception (16, 23).

SDPs are included in a class of secretory proteins that have a signal peptide at the N-terminal and a cell wall signaling signal (CWSS) with the LPXTG motif, which can be identified by the sortase enzyme using the above-mentioned motif. Then, SDPs adhere to the cell wall after T-G being cleaved by the sortase enzyme (37).

Considering the fundamental role of sortase in adhering its substrate to the cell wall in gram-positive bacteria as well as the high importance of a proper adhesion to epithelial cells in improving the functions of probiotic bacteria $(38,39)$, the present study aimed to identify SDPs in LABs.

Given the importance of using probiotics for different purposes, improving different strains by increasing their efficiency, including the engineering of motifs involved in the binding of probiotics can be very helpful. Due to the importance of binding the strains to apply beneficial functional mechanisms, in this study we tried to investigate the SDPs and the LPXTG motif, and recognize the proper amino acid at the X position which has the most important role in the bacterial-host interactions. Due to the fact that the most abundant amino acid in this site is glutamine, its replacement with different amino acids was performed to investigate the effect on the interaction between bacteria and host.

In this research, a comprehensive software (ProtScreen), which included a Projects Section was designed to identify a specific motif or domain in the proteome. The SDP data bank including the specifications of LABs such as their UniProt code, motif recognition, and other SDP characteristics was stored in the above-mentioned software.

The results showed that out of the 165 LAB strains studied, a total of 707 SDP proteins could be identified by sortase A. It is important that, these proteins could be identified in the future studies of lactic acid bacteria, including their functions, binding to the epithelium, examining the interactions between bacteria and the host, and their applications such as drug delivery and oral vaccines. The online ProtScreen software can also be used in the other studies aiming at finding a specific motif in the proteome. SDP data bank can be useful in future studies performed on sortase and its substrates.

Most of the studies on SDPs and LPXTG motif have been performed in pathogenic bacteria as a virulence factor, and there has been no comprehensive study on lactic acid bacteria. For example, previous studies have proved the presence of the LPXTG motif, as a contributing factor in the pathogenesis of Listeria monocytogenes $(40,41)$, Staphylococcus aureus $(42,43)$, Streptococcus pneumoniae (44), and Clostridium difficile (45). However, few studies have been performed on the function of this motif in adhering probiotic bacteria to the gut. According to, Ossowski et al. Proteins with LPXTG in the probiotic $L$. rhamnosus gg strain act as adhesion factors to mucus $(46,47)$. LPXTG proteins have also been shown to stimulate the host's immune system. Mannosespecific adhesion (Msa) in L. plantarum strain WCFS1 is an example of these proteins (48).

A separate study was performed at the genomic and functional analysis of the genes involved in the adhering of 163 probiotic bacterial strains, including lactobacilli, to the HT29 and HT29-MTX cell lins. 156 strains were prepared from native foods along with 7 standard strains.

In that research 14 genes involved in the adhesion process were investigated including sortase A. Also, there were 4 LAB strains. After comparing the results of the two studies, adhesion of the above strains to the two HT29 and HT29-MTX cell lines by Turpin et al., as well as the SDPs, can be concluded that the adhesion of strains to cell lines can have an important relationship with the number of SDPs in probiotic strains. However, to prove this claim, we need to perform more complementary experiments on the adhesion of different strains to cell lines as well as in three-dimensional models of the gastrointestinal tract (49).

\section{Conclusion}

In addition to leucine, proline, threonine, and glycine amino acids in the LPXTG motif, any other amino acid can be placed in the X position, which is attached to the cell wall by SrtA (50). Our results referred to glutamine as the most frequent amino acid, which is naturally present in the LPXTG motif of SDPs. Also Glutamine is a polar uncharged amino acid which plays a key role in binding to surface carbohydrates in membranes (51, 52). Successful adhesion of SDPs to the cell wall requires a proper hydrophobicity in the C-terminal region, LPXTG motif and the N-terminal peptide signal. Signal peptide induces the secretion of SDPs through the Sec-pathway and charged C-terminal tail adheres proteins to the cell wall $(12,23,53)$.

Using bioinformatics tools in the present study, the types of possible amino acids at the X site in the LPXTG sortase cleavage motif in SDPs and their role in interaction with sortase A were investigated.

The results showed that out of 707 SDP proteins studied in different strains of lactic acid bacteria, only two had a characterized structure in UniProt, which were in the species of $E$. faecalis.

Investigation of sortases in the studied strains showed only four sortases with the specified structure, which were present in L. plantarum and L. acidophilus and two sortases in E. faecalis.

Since the aim was to investigate the probiotic lactic acid bacteria, by selecting the L. acidophilus strain (strain ATCC 700396 / NCK56 / N2), which had sortase A with known structure, the modeling method was used to determine the structure of SDP to show the interaction between sortase A and SDP. 
Today, much attention is being directed to lactic acid bacteria for the treatment of various diseases, especially gastrointestinal diseases and also as a useful dietary supplement. Practical use of probiotics for therapeutic applications requires accurate knowledge of their mechanism of action in the gastrointestinal tract.

In the present study, the interaction of sortase A and SDPs as one of the mechanisms involved in the binding of probiotics to the intestinal epithelium was investigated by HADDOCK and CABS-DOCK, the results of which were mentioned previously.

Accordingly, the most abundant amino acid at the X site in the LPXTG motif in the 707 SDP contained in lactic acid bacteria including Lactobacillus, Enterococcus, Lactococcus, Carnobacterium, and Leuconostoc, which are available in the ProtScreen database, was the glutamine.

Docking analysis showed that the lower binding energy was related to the glutamine.

This results and the use of glutamine at X site in the LPXTG motif can be effective in the design and engineering of therapeutic proteins which have role in attachment by sortase mechanism, vaccine design using probiotics containing sortase $A$, and targeted delivery of peptides.

These results proves the importance of functional analysis of SrtA and SDPs in LAB strains, including probiotics. With reference to the importance of adhesion, both pathologically and in terms of the benefits of LAB strains, results of previous laboratory studies on the adhesion of different strains to cell lines and SDPs found in the present study, therefore SDPs are predicted to play key roles in the enhancement and improvement of the adhesion of probiotics to the intestinal wall.

Further investigations of these proteins could help to identify the mechanisms that are involved in the effectiveness of probiotics in therapeutic approach. As mentioned, the structure of many SDPs have not yet been explored, and it is hoped that the structural analysis of such SDPs can be helpful in future studies.

\section{Abbreviations}

LAB: Lactic acid bacteria

GI: Gastrointestinal

SDPs: Sortase Dependent Proteins

Q: Glutamine

CTD: Carboxy-Terminal Domain

SP: Signal Peptide

Sec / SPI: Sec Signal Peptide

Sec / SPII: Lipoprotein Signal Peptide

Tat / SPI: Tat Signal Peptide

\section{Declarations}

\section{Ethics approval and consent to participate}

Not applicable.

\section{Consent for publication}

Not applicable.

\section{Availability of data and materials}

The datasets generated and analyzed during the current study are available in the ProtScreen repository, http://nigebprotscreen.com/.

\section{Competing interests}

The authors declare that they have no competing interests.

\section{Funding}

This research was supported by the National Institute of Genetic Engineering and Biotechnology, Tehran, Iran. Grant number (I-703).

\section{Authors' contributions}

NJ: Data curation, Visualization, Writing- Original draft preparation. ER: Software. ZM: Visualization. SR: Visualization. GA: Supervision, Reviewing and Editing. NA: Supervision, Conceptualization, Methodology. 


\section{Acknowledgments}

The authors are thankful to the National Institute of Genetic Engineering and Biotechnology (NIGEB) for the supports and facilities.

\section{References}

1. Markowiak P. lizewska, K.(2017). Effets des probiotiques, prébiotiques et synbiotiques sur la santé humaine. Nutriments.;9(9).

2. Fuller R. History and development of probiotics. InProbiotics 1992 (pp. 1-8). Springer, Dordrecht.

3. Salminen S, Nybom S, Meriluoto J, Collado MC, Vesterlund S, El-Nezami H. Interaction of probiotics and pathogens-benefits to human health?. Current opinion in biotechnology. 2010 Apr 1;21(2):157-67.

4. Ljungh $A$, Wadstrom T. Lactic acid bacteria as probiotics. Current issues in intestinal microbiology. 2006 Sep 1;7(2):73-90.

5. Binetti AG, Burns PG, Tomei D, Reinheimer JA, Vinderola CG. Probiotics regulation in Latin American Countries.

6. Yoon KY, Woodams EE, Hang YD. Production of probiotic cabbage juice by lactic acid bacteria. Bioresource technology. 2006 Aug 1;97(12):1427-30.

7. Hye-Ji K, Sin-Hyeog I. Probiotics as an immune modulator. Journal of Nutritional Science and Vitaminology. 2015;61:S103-5.

8. Garriga M, Rubio R, Aymerich T, Ruas-Madiedo P. Potentially probiotic and bioprotective lactic acid bacteria starter cultures antagonise the Listeria monocytogenes adhesion to HT29 colonocyte-like cells. Beneficial microbes. 2015 Jan 1;6(3):337-43.

9. Rinkinen M, Jalava K, Westermarck E, Salminen S, Ouwehand AC. Interaction between probiotic lactic acid bacteria and canine enteric pathogens: a risk factor for intestinal Enterococcus faecium colonization?. Veterinary Microbiology. 2003 Mar 20;92(1-2):111-9.

10. Campana R, van Hemert S, Baffone W. Strain-specific probiotic properties of lactic acid bacteria and their interference with human intestinal pathogens invasion. Gut Pathogens. 2017 Dec;9(1):1-2.

11. Skeie S, Lindberg C, Narvhus J. Development of amino acids and organic acids in Norvegia, influence of milk treatment and adjunct Lactobacillus. International Dairy Journal. 2001 Jul 11;11(4-7):399-411.

12. Jacobitz AW, Kattke MD, Wereszczynski J, Clubb RT. Sortase transpeptidases: structural biology and catalytic mechanism. InAdvances in protein chemistry and structural biology 2017 Jan 1 (Vol. 109, pp. 223-264). Academic Press.

13. Turroni F, Serafini F, Foroni E, Duranti S, Motherway MO, Taverniti V, Mangifesta M, Milani C, Viappiani A, Roversi T, Sánchez B. Role of sortase-dependent pili of Bifidobacterium bifidum PRL2010 in modulating bacterium-host interactions. Proceedings of the National Academy of Sciences. 2013 Jul 2;110(27):11151-6.

14. Pishesha N, Ingram JR, Ploegh HL. Sortase A: a model for transpeptidation and its biological applications. Annual review of cell and developmental biology. 2018 Oct 6;34:163-88.

15. Hendrickx AP, Budzik JM, Oh SY, Schneewind O. Architects at the bacterial surface-sortases and the assembly of pili with isopeptide bonds. Nature reviews Microbiology. 2011 Mar;9(3):166-76.

16. Dramsi S, Trieu-Cuot P, Bierne H. Sorting sortases: a nomenclature proposal for the various sortases of Gram-positive bacteria. Research in microbiology. 2005 Apr 1;156(3):289-97.

17. Comfort D, Clubb RT. A comparative genome analysis identifies distinct sorting pathways in gram-positive bacteria. Infection and immunity. 2004 May $1 ; 72(5): 2710-22$

18. Marraffini LA, DeDent AC, Schneewind O. Sortases and the art of anchoring proteins to the envelopes of gram-positive bacteria. Microbiology and Molecular Biology Reviews. 2006 Mar 1;70(1):192-221.

19. Mazmanian SK, Ton-That H, Su K, Schneewind O. An iron-regulated sortase anchors a class of surface protein during Staphylococcus aureus pathogenesis. Proceedings of the National Academy of Sciences. 2002 Feb 19;99(4):2293-8.

20. Manzano C, Contreras-Martel C, El Mortaji L, Izoré T, Fenel D, Vernet T, Schoehn G, Di Guilmi AM, Dessen A. Sortase-mediated pilus fiber biogenesis in Streptococcus pneumoniae. Structure. 2008 Dec 12;16(12):1838-48.

21. Neiers F, Madhurantakam C, Fälker S, Manzano C, Dessen A, Normark S, Henriques-Normark B, Achour A. Two crystal structures of pneumococcal pilus sortase $C$ provide novel insights into catalysis and substrate specificity. Journal of molecular biology. 2009 Oct 30;393(3):704-16.

22. Bradshaw WJ, Davies AH, Chambers CJ, Roberts AK, Shone CC, Acharya KR. Molecular features of the sortase enzyme family. The FEBS journal. 2015 Jun;282(11):2097-114.

23. Spirig T, Weiner EM, Clubb RT. Sortase enzymes in Gram-positive bacteria. Molecular microbiology. 2011 Dec;82(5):1044-59.

24. Schneewind O, Missiakas D. Sec-secretion and sortase-mediated anchoring of proteins in Gram-positive bacteria. Biochimica et Biophysica Acta (BBA)Molecular Cell Research. 2014 Aug 1;1843(8):1687-97.

25. Cascioferro S, Totsika M, Schillaci D. Sortase A: an ideal target for anti-virulence drug development. Microbial pathogenesis. 2014 Dec 1;77:105-12.

26. Siegel SD, Liu J, Ton-That H. Biogenesis of the Gram-positive bacterial cell envelope. Current opinion in microbiology. 2016 Dec 1;34:31-7.

27. Bennett M, Gilroy DW. Lipid mediators in inflammation. Myeloid Cells in Health and Disease: A Synthesis. 2017 Feb 1:343-66.

28. Arnesano F, Banci L, Bertini I, Bonvin AM. A docking approach to the study of copper trafficking proteins: Interaction between metallochaperones and soluble domains of copper ATPases. Structure. 2004 Apr 1;12(4):669-76.

29. Armenteros JJ, Tsirigos KD, Sønderby CK, Petersen TN, Winther O, Brunak S, von Heijne G, Nielsen H. SignalP 5.0 improves signal peptide predictions using deep neural networks. Nature biotechnology. 2019 Apr;37(4):420-3. 
30. Gasteiger E, Hoogland C, Gattiker A, Wilkins MR, Appel RD, Bairoch A. Protein identification and analysis tools on the ExPASy server. InThe proteomics protocols handbook 2005 (pp. 571-607). Humana press.

31. De Vries SJ, Van Dijk AD, Krzeminski M, van Dijk M, Thureau A, Hsu V, Wassenaar T, Bonvin AM. HADDOCK versus HADDOCK: new features and performance of HADDOCK2. 0 on the CAPRI targets. Proteins: structure, function, and bioinformatics. 2007 Dec;69(4):726-33.

32. Kurcinski M, Jamroz M, Blaszczyk M, Kolinski A, Kmiecik S. CABS-dock web server for the flexible docking of peptides to proteins without prior knowledge of the binding site. Nucleic acids research. $2015 \mathrm{Jul}$ 1;43(W1):W419-24.

33. Simon O, Vahjen W, Scharek L. Micro-organisms as feed additives-probiotics. Advances in pork Production. 2005;16(2):161-7.

34. Hill C, Guarner F, Reid G, Gibson GR, Merenstein DJ, Pot B, Morelli L, Canani RB, Flint HJ, Salminen S, Calder PC. Expert consensus document: The International Scientific Association for Probiotics and Prebiotics consensus statement on the scope and appropriate use of the term probiotic. Nature reviews Gastroenterology \& hepatology. 2014 Aug;11(8):506.

35. Lee YK. Selection and maintenance of probiotic microorganisms. Handbook of probiotics and prebiotics. Wiley-VCH, Weinheim, Germany. 2009 Feb 17:177-87.

36. Plavec TV, Berlec A. Engineering of lactic acid bacteria for delivery of therapeutic proteins and peptides. Applied microbiology and biotechnology. 2019 Mar 1;103(5):2053-66.

37. Maresso AW, Schneewind O. Sortase as a target of anti-infective therapy. Pharmacological reviews. 2008 Mar 1;60(1):128-41.

38. Call E, Klaenhammer T. Relevance and application of sortase and sortase-dependent proteins in lactic acid bacteria. Frontiers in microbiology. 2013 Apr 8;4:73.

39. Call EK, Goh YJ, Selle K, Klaenhammer TR, O'Flaherty S. Sortase-deficient lactobacilli: effect on immunomodulation and gut retention. Microbiology. 2015 Feb 1;161(Pt 2):311.

40. Mariscotti JF, Quereda JJ, Graciela Pucciarelli M. Contribution of sortase A to the regulation of Listeria monocytogenes LPXTG surface proteins. International microbiology. 2012 Mar 1.

41. Rodrigues C, Machado E, Ramos H, Peixe L, Novais Â. Expansion of ESBL-producing Klebsiella pneumoniae in hospitalized patients: a successful story of international clones (ST15, ST147, ST336) and epidemic plasmids (IncR, IncFIIK). International Journal of Medical Microbiology. 2014 Nov 1;304(8):11008.

42. Ythier M, Resch G, Waridel P, Panchaud A, Gfeller A, Majcherczyk P, Quadroni M, Moreillon P. Proteomic and transcriptomic profiling of Staphylococcus aureus surface LPXTG-proteins: correlation with agr genotypes and adherence phenotypes. Molecular \& Cellular Proteomics. 2012 Nov 1;11(11):1123-39.

43. Khodaparast L. The Possible Role of the Staphylococcus epidermidis LPxTG Surface Protein SesC in Biofilm Formation and its use as a potential vaccine target.

44. Mitchell AM, Mitchell TJ. Streptococcus pneumoniae: virulence factors and variation. Clinical Microbiology and Infection. 2010 May 1;16(5):411-8.

45. Hensbergen PJ, Klychnikov OI, Bakker D, van Winden VJ, Ras N, Kemp AC, Cordfunke RA, Dragan I, Deelder AM, Kuijper EJ, Corver J. A novel secreted metalloprotease (CD2830) from Clostridium difficile cleaves specific proline sequences in LPXTG cell surface proteins. Molecular \& Cellular Proteomics. 2014 May 1;13(5):1231-44.

46. von Ossowski I, Satokari R, Reunanen J, Lebeer S, De Keersmaecker SC, Vanderleyden J, de Vos WM, Palva A. Functional characterization of a mucusspecific LPXTG surface adhesin from probiotic Lactobacillus rhamnosus GG. Applied and environmental microbiology. 2011 Jul 1;77(13):4465-72.

47. Gross G, van Der Meulen J, Snel J, van Der Meer R, Kleerebezem M, Niewold TA, Hulst MM, Smits MA. Mannose-specific interaction of Lactobacillus plantarum with porcine jejunal epithelium. FEMS Immunology \& Medical Microbiology. 2008 Nov 1;54(2):215-23.

48. Rigi G, Farhadpour M, Ghasempour A, Ahmadian G, Aboul-Enein HY. Correction to: Per Aqueous Liquid Chromatography (PALC) as a Simple Method for Native Separation of Protein A. Chromatographia. 2017 Jan 1;80(12):1827-.

49. Turpin W, Humblot C, Noordine ML, Thomas M, Guyot JP. Lactobacillaceae and cell adhesion: genomic and functional screening. PLoS One. 2012 May 31;7(5):e38034.

50. Boekhorst J, de Been MW, Kleerebezem M, Siezen RJ. Genome-wide detection and analysis of cell wall-bound proteins with LPxTG-like sorting motifs. Journal of bacteriology. $2005 \mathrm{Jul}$ 1;187(14):4928-34.

51. Cherepanova N, Shrimal S, Gilmore R. N-linked glycosylation and homeostasis of the endoplasmic reticulum. Current opinion in cell biology. 2016 Aug 1;41:57-65.

52. Wang B, Wu G, Zhou Z, Dai Z, Sun Y, Ji Y, Li W, Wang W, Liu C, Han F, Wu Z. Glutamine and intestinal barrier function. Amino acids. 2015 Oct 1;47(10):2143-54.

53. Clancy KW. Melvin J a, McCafferty DG. Sortase transpeptidases: insights into mechanism, substrate specificity, and inhibition. Biopolymers. 2010;94:38596.

\section{Figures}




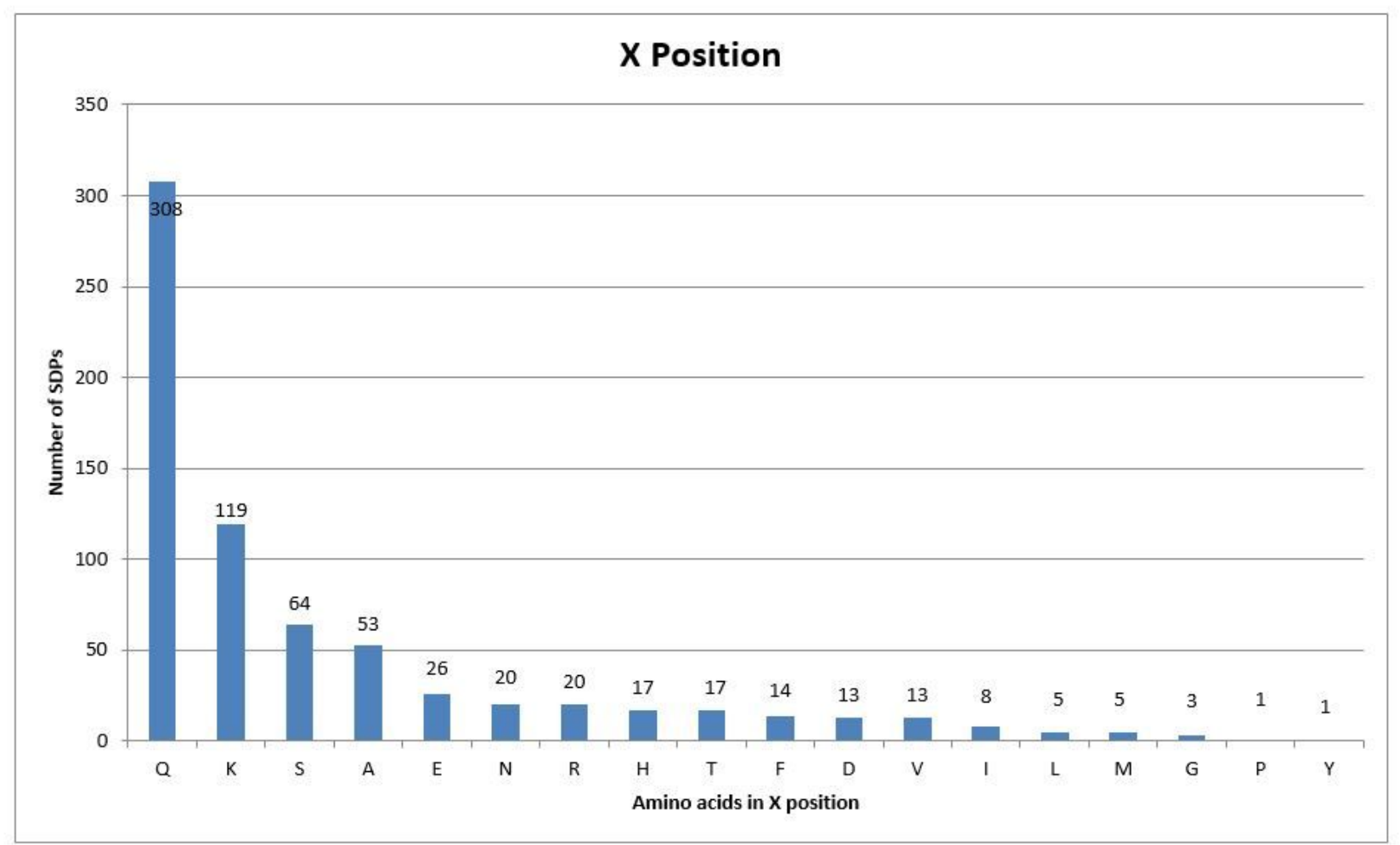

Figure 1

Diagram of the number and the type of amino acids in $\mathrm{X}$ position. 
A

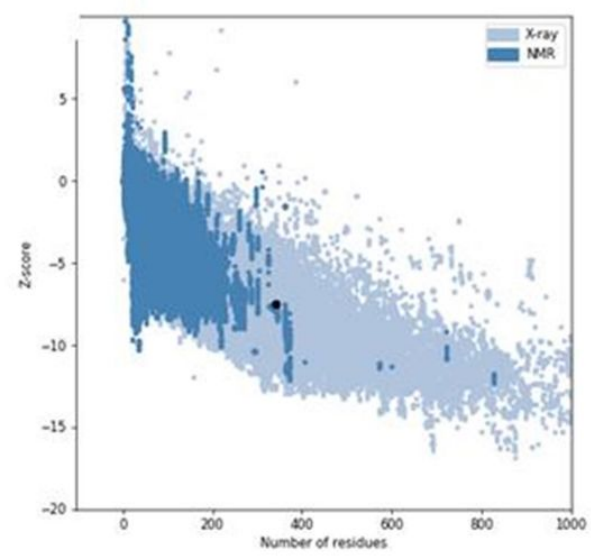

B

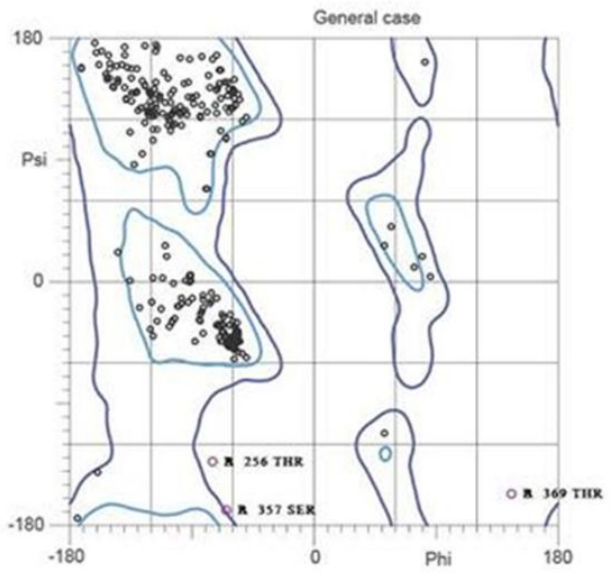

Figure 2

Evaluation and validation of the model made of SDP with LPQTG motif; A: ProSA, B: Ramachandran map.

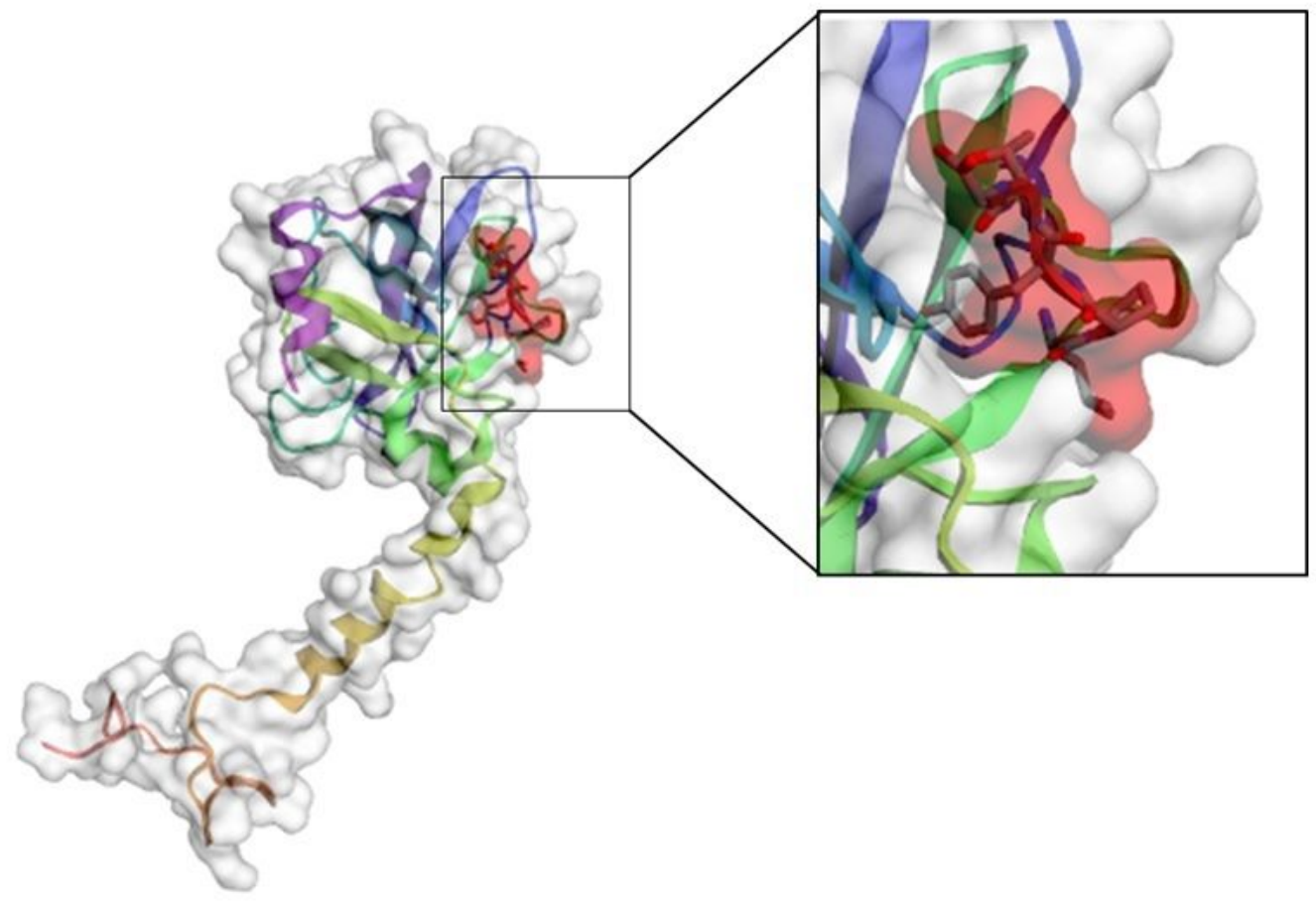


Figure 3

Interaction between sortase A and LPQTG peptide. Red: LPQTG peptide of the SDP part, green-blue: Sortase A part.

\section{Supplementary Files}

This is a list of supplementary files associated with this preprint. Click to download.

- Additionalfile1.xlsx

- Additionalfile2.xlsx 